Leemans, K., Block, L. van den, Stichele, R. Vander, Francke, A.L., Deliens, L., Cohen, J. How to implement quality indicators successfully in palliative care services: perceptions of team members about facilitators of and barriers to implementation. Supportive Care in Cancer: 2015,7 23(12), 3503-3511

\begin{tabular}{|l|l|}
\hline $\begin{array}{l}\text { Postprint } \\
\text { Version }\end{array}$ & 1.0 \\
\hline Journal website & http://link.springer.com/article/10.1007\%2Fs00520-015-2687-8 \\
\hline Pubmed link & $\underline{\text { http://www.ncbi.nlm.nih.gov/pubmed/?term=25832893 }}$ \\
\hline DOI & $10.1007 / \mathrm{s} 00520-015-2687-8$ \\
\hline
\end{tabular}

This is a NIVEL certified Post Print, more info at http://www.nivel.eu

\title{
How to implement quality indicators successfully in palliative care services: perceptions of team members about facilitators of and barriers to implementation
}

\author{
KATHLEEN LEEMANS ${ }^{1}$, LIEVE VAN DEN BLOCK ${ }^{1,2}$, ROBERT VANDER STICHELE ${ }^{1,3}$, \\ ANNEKE L. FRANCKE ${ }^{4,5}$, LUC DELIENS ${ }^{1,4}$ AND JOACHIM COHEN ${ }^{1}$ \\ (1) End-of-Life Care Research Group Vrije Universiteit Brussel (VUB) and Ghent University, \\ Laarbeeklaan 103, 1090 Brussels, Belgium \\ (2) Department of Family Medicine and Chronic Care, Vrije Universiteit Brussel (VUB), \\ Brussels, Belgium \\ (3) Heymans Insitute, Department of Pharmacology, Ghent University, Ghent, Belgium \\ (4) Department of Public and Occupational Health, EMGO Institute for Health and Care \\ Research, VU University Medical Center, Amsterdam, The Netherlands \\ (5) NIVEL. Netherlands Institute for Health Services Research, Utrecht, The Netherlands
}

\begin{abstract}
Purpose: There is an increasing demand for the use of quality indicators in palliative care. With previous research about implementation in this field lacking, we aimed to evaluate the barriers to and facilitators of implementation. Methods: Three focus group interviews were organized with 21 caregivers from 18 different specialized palliative care services in Belgium. Four had already worked with the indicators during a pilot study. The focus group discussions were transcribed verbatim and analyzed using the thematic framework approach. Results: The caregivers anticipated that a positive attitude by the team towards quality improvement, the presence of a good leader, and the possible link between quality indicators and reimbursement might facilitate the implementation of quality indicators in specialized palliative care services. Other facilitators concerned the presence of a need to demonstrate quality of care, to perform improvement actions, and to learn from other caregivers and services in the field. A negative attitude by caregivers towards quality measurement and a lack of skills, time, and staff were mentioned as barriers to successful implementation.
\end{abstract}


Leemans, K., Block, L. van den, Stichele, R. Vander, Francke, A.L., Deliens, L., Cohen, J. How to implement quality indicators successfully in palliative care services: perceptions of team members about facilitators of and barriers to implementation. Supportive Care in Cancer: 2015,7 23(12), 3503-3511

Conclusion: Palliative caregivers anticipate a number of opportunities and problems when implementing quality indicators. These relate to the attitudes of the team regarding quality measurement; the attitudes, knowledge, and skills of the individual caregivers within the team; and the organizational context and the economic and political context. Training in the advantages of quality indicators and how to use them is indispensable, as are structural changes in the policy concerning palliative care, in order to progress towards systematic quality monitoring.

\section{BACKGROUND}

Quality indicators are of great importance in the field of palliative care as they can provide information to caregivers on areas that require improvement and enhance transparency for patients and their families [1-6]. Administrators and policy makers can use the information they provide to make quality improvements within care services (internal aim) and for comparisons between various care services (external aim) [7-9]. Quality indicators are defined as measurable aspects of care addressing a specific quality issue or a related outcome [10-13]. Hitherto, efforts to develop quality indicators for palliative care have mainly focused on characteristics of palliative care for cancer patients using administrative data [14-17] or are focused on outcome measures rather than on producing well-defined quality indicators $[7,8,18]$. Only a few quality indicator sets have been developed specifically to monitor the quality of overall palliative care and they tend not to focus on all its various domains $[19,20]$. In Belgium, we have developed a comprehensive quality indicator set which has been tested and judged as feasible and valid [21,22]. It takes into account the perspectives of patients, family carers, professional caregivers, and policy makers. The quality indicator set is meant for use in specialized palliative care services ie palliative care units, palliative support teams in hospitals, and multidisciplinary palliative home care teams.

In order to be used systematically on a wide scale to monitor and subsequently improve the quality of palliative care, the quality indicators firstly need to be implemented successfully within palliative care services. Such implementation process requires extra attention and good preparation as it will not follow automatically from development and dissemination [23, 24]. Grol et al. have suggested a five-step plan for successful implementation of an innovation in health care [25]. After an innovation is developed (step 1), barriers and facilitators need to be identified (step 2) in order to develop implementation strategies (step 3) and an implementation plan (step 4) that can be used and evaluated in practice (step 5). Insight into barriers to and facilitators of implementation of QIs - step 2-provides the basis to ensure that implementation strategies are being adapted to specific situations, innovations, and target groups [26]. Given the increasing demand for the use of quality indicators in palliative care services across different countries, the difficulties inherent in the implementation of quality indicators, and the lack of research about barriers and facilitators of implementation in palliative care services, a study on how to implement quality indicators successfully in palliative care services was needed. 
Leemans, K., Block, L. van den, Stichele, R. Vander, Francke, A.L., Deliens, L., Cohen, J. How to implement quality indicators successfully in palliative care services: perceptions of team members about facilitators of and barriers to implementation. Supportive Care in Cancer: 2015,7 23(12), 3503-3511

Although two previous studies [27, 28], one concerning dementia care settings and one concerning intensive care units, have provided useful information about possible barriers and facilitators for quality indicator implementation $[27,28]$, they did not specifically look at the context of specialist palliative care and it remains unclear whether their findings can be generalized to this context. Palliative care has its own unique and peculiar issues and organization [29-32]. Hence, this study aims to identify possible conditions that facilitate or impede implementation of quality indicators for specialized palliative care services, from the professional palliative caregiver's perspective, across the three types of palliative care services, i.e., palliative care units, mobile palliative support teams in hospitals, and multidisciplinary palliative home care teams.

\section{METHODS}

\section{Design}

Identification of barriers and facilitators as suggested by Grol et al. [25] is best addressed through a qualitative design as this allows for a more in-depth evaluation of underlying concerns and objections of relevant agents in the field of interest, i.e., palliative care. Therefore, focus group interviews were held with professional caregivers of palliative home and hospital care about the use of the developed quality indicator set in their service. The focus group approach allows for more insight into reasons for considering or not considering the use of the quality indicators for quality measurement within specialized palliative care services and even into possible solutions [33].

\section{The quality indicator set (i.e., innovation aspect)}

The quality indicator set was developed as a new innovation for palliative care services in Flanders (the Dutch-speaking part of Belgium) and consists of a comprehensive minimal set (31 indicators) and three optional thematic modules covering all domains of palliative care: physical aspects of care, psychosocial and spiritual/existential aspects of care, communication and care planning, coordination and continuity of care, type of care and circumstances surrounding death, and structure of care. To measure the indicators, questionnaires are sent to patients, family carers, and professional caregivers using a cross-sectional inclusion method. This implies that the palliative care services list two groups of patients on 1 day: (1) all patients that are being supported (i.e., all those enrolled and still alive) by the palliative care service on that specific day and (2) all patients enrolled in the service but who had died in the previous 4 weeks to 4 months. For the first group, a questionnaire is provided to the patient and the most important professional carer at that moment, as decided by the coordinator of the study. This is the caregiver of the team that spends the most time at the bed of the patient. For the second group, a questionnaire is sent to the most important family carer and professional carer (or the family physician for patients who died at home). The combination of both groups allows evaluation of both processes and outcomes of care and aspects of care in the days surrounding death (including aftercare for the family). After receiving all completed questionnaires from the respondents, the anonymized responses are sent to an independent research team which calculates the quality indicator scores and feeds 
Leemans, K., Block, L. van den, Stichele, R. Vander, Francke, A.L., Deliens, L., Cohen, J. How to implement quality indicators successfully in palliative care services: perceptions of team members about facilitators of and barriers to implementation. Supportive Care in Cancer: 2015,7 23(12), 3503-3511

them back to the service in the form of a report. The team members then, in principal, plan a meeting to interpret the scores, distil working points for the service, and set up an action plan to improve quality of care. This procedure needs to be repeated every 6 months within one service to be able to measure the effects of improvement actions. Figure 1 present a schematic overview of the procedure; the whole procedure is described elaborately elsewhere [21,22].

\section{[FIGURE 1]}

\section{Participants in the focus groups}

Participants were purposefully recruited to participate in a focus group interview about the implementation of quality indicators within their specialized palliative care service. We wanted physicians and nurses as well as psychologists to participate as all these types of caregivers might have different views on quality measurement because of their background, education, and work experience. We deemed it important for the dynamics of the discussion that persons who already had experience with quality indicator measurement within their service (through our previous feasibility study, [22]) were represented in each focus group. Additionally, the three types of palliative care services needed to be represented. An invitation was spread through the network coordinators of the 15 different palliative care networks in Flanders. Additionally, an invitation was sent directly to all services that had participated in the previous feasibility study.

\section{Procedures}

Three focus group interviews were held, one for the palliative care units (PCUs), one for the palliative support teams in hospitals (PSTs), and one for the multidisciplinary palliative home care teams (MHTs). We made this choice because we anticipated that the different organization of each type of service might evoke different barriers and facilitators. Initially, for the MHTs, no physicians were found available after sending around the invitation, so extra recruitment was conducted by personal e-mail and telephone. Each focus group interview was led by an experienced moderator using an interview guide to structure the discussion (Table 1). The interview guide was developed and reviewed within a multidisciplinary research team of psychologists (KL, LVDB), sociologists (JC, LD), a physician (RVS), and a nurse (ALF). Before the start of each focus group interview, all participants received the full manual on how to use the quality indicator set in palliative care services for quality measurement (specific manuals were developed for each of the three types of palliative care services). They were asked to read through the manual in advance, especially the measurement procedure. Each discussion lasted for $90 \mathrm{~min}$ and was audiotaped, for which all participants gave consent. Both the meetings and transcriptions, which were transcribed verbatim, were in Dutch.

\section{[TABLE 1]}

\section{Analysis}

We performed thematic analysis [34] on the three transcripts, supported by NVivo software. The thematic framework approach used consisted of five interconnected stages: familiarization, identifying a thematic framework, indexing (coding), charting, and interpretation. The first author (KL) performed thematic coding using 
Leemans, K., Block, L. van den, Stichele, R. Vander, Francke, A.L., Deliens, L., Cohen, J. How to implement quality indicators successfully in palliative care services: perceptions of team members about facilitators of and barriers to implementation. Supportive Care in Cancer: 2015,7 23(12), 3503-3511

the existing framework of various levels of barriers and facilitators developed by Grol et al. [26]. This model defines six levels of the healthcare system to examine barriers and facilitators: level of innovation (in this study the quality indicator set for palliative care services), level of individual caregiver, level of patient (in this study replaced by respondent to the questionnaire because of the nature of the innovation), level of organizational context, level of social context, and level of economic and political context. Based on this analysis, a tentative framework was identified dividing the six existing healthcare levels into subthemes that arose during coding. The tentative framework and one of the three transcripts were then presented to a second researcher (JC). Both researchers discussed the differences and reached consensus on the final thematic framework, which was then applied to all interview transcripts. During the coding and charting, the researchers took into account the possibility of identifying new levels of healthcare not yet defined in the literature (but none were found).

\section{Ethics}

A signed informed consent was obtained from each participant before the start of the focus group interview. Anonymity was assured by removing participant information that could lead to identification from transcripts. No sociodemographic characteristics were acquired from the participants. The current study is part of a larger feasibility project for which the protocol was approved by the Ethical Review Board of Brussels University Hospital of the Vrije Universiteit Brussel (143201112708). Because of the involvement of professional caregivers only, no additional ethics committee approval was required for the focus group interviews with the members of the palliative care teams.

\section{RESULTS}

In total, 21 professional caregivers $(n=7, n=9, n=5)$ from 18 different palliative care services $(n=7, n=7, n=4)$ participated in the three focus group interviews (Table 2). Four of the 21 caregivers had already worked with the quality indicators during our feasibility study [21]. For the PCU, the invited physician cancelled $1 \mathrm{~h}$ before the start of the interview due to family circumstances. Despite the extra recruitment effort, no physician was found to participate in the MHT. The caregivers identified conditions facilitating or impeding implementation at all levels mentioned in the framework by Grol et al. except for the social context (Table 3). We took the liberty of renaming the levels in the framework where this better matched the meanings within this study.

\section{[TABLE 2] [TABLE 3]}

\section{Attitudes of the team regarding quality measurement (i.e., level of the innovation)}

Presence of a need to demonstrate quality of care

Participants explained that the quality indicators would serve the need to prove their quality of care in an appropriate manner. The data they currently collect for administrators are mostly quantitative process figures, and the caregivers felt that these do not adequately cover the relevant aspects of their care. The need to 
Leemans, K., Block, L. van den, Stichele, R. Vander, Francke, A.L., Deliens, L., Cohen, J. How to implement quality indicators successfully in palliative care services: perceptions of team members about facilitators of and barriers to implementation. Supportive Care in Cancer: 2015,7 23(12), 3503-3511

demonstrate their quality of care was identified as facilitating implementation as quality indicators can provide that information.

Often we observe certain things with patients, but if we ask for them we get different results $[\ldots]$ those things we want to measure. Kind of like customer satisfaction.

(Network coordinator, MHT)

An identified need for evidence-based improvement trajectories Most caregivers explained that they were already setting improvement goals within their teams and taking action to reach them, but they felt that collecting evidence was necessary to see any effective improvement. Because quality indicators can provide such evidence and can be embedded into improvement trajectories, this need was seen as facilitating implementation.

[...] And you could see the result of the action you took. Otherwise we did something but did we benefit from it? If you don't measure it, you won't know. Then it is a subjective feeling. (Head nurse 1, PCU)

Presence of a desire to exchange ideas with and learn from other palliative care services

Most caregivers expressed a desire to exchange quality information with other teams and services in order to learn from each other. They said that they could use the quality indicators to reveal other teams' specialties.

It is important to close the circle, to extract goals. Not just for yourself but to see if we are improving. And to position yourself towards others. What teams are good at, what we can learn from each other. (Network coordinator, MHT)

Moreover, caregivers expressed the desire for benchmarking the quality indicator scores, as it would provide them with important information on how they are performing compared with similar services in their region.

\section{Attitudes, knowledge, and skills within the team (i.e., level of individual caregiver) \\ Perceptions of quality indicators as an individual evaluation}

According to the caregivers, team members' incorrect perception of quality indicators as an individual instead of a team evaluation impedes implementation. It will provide positive points and working points. And if you need to improve these working points you have to be careful that you don't accuse individual caregivers. (Head nurse, MHT)

Lack of knowledge and skills to work with quality indicators

All caregivers agreed that they had insufficient skills and knowledge about how to measure and calculate the quality indicators. This was perceived as impeding their ability to start working with the quality indicators.

Respondents suggested that extensive training is provided on how to measure, interpret, and use indicators for quality improvements.

Attitude of quality measurement as something outside the responsibility of caregivers Most caregivers expected the other team members to be worried about the capacity of the team and the timing when proposing to start measuring the quality of their care. For them, this attitude would impede implementation.

Does the team see the possibility in this stadium, considering the evolution in the team at the moment, to perform it? Not just for the work load but are they ready to do something with it? (Psychologist 1, MHT) 
Leemans, K., Block, L. van den, Stichele, R. Vander, Francke, A.L., Deliens, L., Cohen, J. How to implement quality indicators successfully in palliative care services: perceptions of team members about facilitators of and barriers to implementation. Supportive Care in Cancer: 2015,7 23(12), 3503-3511

Furthermore, some caregivers pointed out that they did not see themselves as capable of assessing quality measurement and improvement; most saw it as the task of management.

\section{Anxiety about harming respondents to the questionnaires (i.e., level of respondents)}

A tendency to protect vulnerable patients and families

This was identified as a condition that would impede implementing quality indicators Some of the caregivers of the MHT and PST focus groups indicated that they had previously wanted to start measuring the quality of their care, e.g., by systematically asking patients and their families questions but had not done so out of fear that it would disturb them, and they based these concerns on certain experiences.

You are in that area, with people experiencing major concerns. [...] how can you start measuring things? (Head nurse 2, PST)

Anxiety about influencing the relationship with the family physician

This was named as a barrier, as a questionnaire needs to be sent to the family physician to collect quality information. Caregivers of the MHT were concerned about disturbing the relationship with the family physician, as they are the key figures for the patient in their care.

\section{Structures and organization of care (i.e., level of organizational context)}

Lack of time and staff to perform quality measurement

All caregivers interviewed worried about the workload and the time investment needed to implement the quality indicators. They mentioned that the actual lack of time and staff would impede the implementation of quality indicators.

I think you will have to involve someone extra to do that. Because at that moment, you cannot perform patient care together with quality measurement. (Nurse, PCU) PST and PCU caregivers saw a possible solution in involving the management. If they could be convinced of the advantages to the team and the hospital, they might be willing to give extra support and resources to overcome this barrier.

Instabilities within the team

Some caregivers were concerned about absences of team members due to prolonged illness, relocations, and other project involvements. As long as not every team member is available, they felt it would be impossible to commit to quality measurement.

At the time a team experiences a lot of pressure, the quality of the care decreases. That is not the right time to perform a quality measurement, when you feel such a pressure. (Head nurse 1, MHT)

Therefore, the caregivers felt the need to plan such quality measurement well in advance to overcome potential hurdles.

Presence of electronic patient records

Most caregivers wanted to use their electronic patient records for the listing of patients as well as reporting the indicators. They explained that it could automatize the quality measurement, reduce the workload, and hence facilitate implementation. However, not all palliative care services have access to well-functioning electronic patient files.

Presence for a good leader to guide the quality measurement 
Leemans, K., Block, L. van den, Stichele, R. Vander, Francke, A.L., Deliens, L., Cohen, J. How to implement quality indicators successfully in palliative care services: perceptions of team members about facilitators of and barriers to implementation. Supportive Care in Cancer: 2015,7 23(12), 3503-3511

All caregivers explained that in order to use quality information to set improvement goals within their service and tackle them, a strong coordinator is needed to overview all tasks, motivate the team members, and facilitate the implementation.

[...] I don't think you can separate it from the coordinator. You can delegate as coordinator, but you cannot, or even you may not let go. (Head nurse 2, PCU) Interest in quality management from the directors

Some caregivers indicated that their team or hospital had already been searching for ways to measure and improve the quality of their care. According to the caregivers, such interest in quality measurement facilitates the implementation of quality indicators.

This year at our hospital, initiated by the directors, they wanted to find out how they could measure the quality on the different wards. So the question was raised of how we could do it in our team. (Psychologist 2, PST)

\section{Economic and political context}

Willingness to transfer results of quality measurement to the government to show how they are performing This facilitates implementation of quality indicators. All caregivers pointed out that the government is busy developing controlling systems throughout all areas of health care. They think it is important for the government to take into account the quality of care alongside more quantitative figures because everyone agrees that it is important to strive for high-quality care.

[...] everyone is convinced that you have to try to provide good quality care. Then they have to measure that together with the quantitative figures. I don't mind. They will measure anyway. Because they have to hand out their money. (Head nurse 1, PCU)

Reimbursement for using quality indicators

Caregivers stated that being reimbursed for participating into quality indicator measurement would facilitate successful implementation. They argued that because of the existing shortcoming of resources in palliative care, especially shortness of staff, such extra reimbursement is necessary to guarantee measuring the quality indicators on a systematic basis within the palliative care services.

Possibility to link quality indicators to hospital accreditation

Caregivers of the PST and PCU mentioned that their hospital management had recently engaged in achieving accreditation. They said that this engagement would facilitate the use of quality indicators in palliative care services, as the quality indicators could help them achieve the accreditation.

I think it might be a strong point if you can convince your management that it can play a role in achieving accreditation. I think it can even determine which improvement actions to choose for. (Head nurse 1, PCU)

As many hospitals in Flanders have recently enrolled for accreditation, caregivers mentioned that it is the right time to implement the quality indicators in the field of palliative care.

\section{DISCUSSION}

Team members of palliative care services anticipate a number of opportunities and problems related to the implementation of quality indicators. These relate to attitudes of the team regarding quality measurement; attitudes, knowledge, and skills of the 
Leemans, K., Block, L. van den, Stichele, R. Vander, Francke, A.L., Deliens, L., Cohen, J. How to implement quality indicators successfully in palliative care services: perceptions of team members about facilitators of and barriers to implementation. Supportive Care in Cancer: 2015,7 23(12), 3503-3511

individual caregivers; a cautiousness about harming the respondents to the questionnaires; the organizational context; and the economic and political context. Similar problems and opportunities for quality indicators were found across the three types of specialized palliative care services involved in this study, although certain specific opportunities and problems emerged that were inherent in the specific functioning and organization of the services.

The findings of this qualitative study confirm many barriers and facilitators in the literature concerning implementation of quality measurement such as lack of time and skills, the need for good leadership and training, using electronic patient files, and receiving reimbursement $[27,28,35-37]$. All these factors except lack of skills were mentioned in all three focus groups in this study. Other facilitators that were mentioned and have not already been described in the literature concerned the need to demonstrate quality of care, to perform improvement actions, and to learn from other services in the field.

Despite strong similarities across the three types of services, some differences were found. Most were linked to the specific organization of the services, for example, the anxiety about harming the relationship with the family physician was present particularly in the multidisciplinary home care teams as they provide him or her with palliative care support. The possibility of linking quality indicators to hospital accreditation was a facilitating condition mentioned in both hospital-based services. Therefore, in order to create the optimal environment for successful implementation, specific strategies need to be developed. Once implementation is started based on a well-considered implementation plan, process evaluation is needed to evaluate the quality of the implementation process and the effectiveness of the strategies and to identify additional barriers and facilitators [25]. Throughout the whole implementation process, involvement of stakeholders should be retained to evaluate critically the progression towards a systematic quality monitoring system $[9,38]$.

\section{Limitations}

Several limitations of our study need to be acknowledged. First, we chose to identify barriers and facilitators only from the perspective of the professional caregivers. We did not involve other stakeholders such as patients, family members, or administrators. However, caregivers are involved in the implementation, and it is they who will collect the data for the quality indicators. Moreover, the quality indicators and accompanying measurement procedures have already been validated with patients and family members as part of a feasibility study. A second limitation involves the fact that a palliative care physician was not present in the focus groups of the palliative care units and the multidisciplinary palliative home care teams. We did not consider this to be a major issue as our feasibility study taught us that it is mostly the nurses and head nurses rather than consulting physicians who would have a substantial role in the implementation process of the quality indicators.

\section{CONCLUSION AND IMPLICATIONS}

In this study, palliative care professionals indicated that a positive attitude of the team towards quality improvement, the presence of electronic records, and the presence of a good leader would facilitate the implementation of quality indicators in specialized palliative care services. On the other hand, a negative attitude by some individual caregivers towards quality measurement could impede successful 
Leemans, K., Block, L. van den, Stichele, R. Vander, Francke, A.L., Deliens, L., Cohen, J. How to implement quality indicators successfully in palliative care services: perceptions of team members about facilitators of and barriers to implementation. Supportive Care in Cancer: 2015,7 23(12), 3503-3511

implementation. Furthermore, shortage of caregivers' time and staff shortages might impede the use of quality indicators within the services. Nevertheless, the possible link between quality indicators and funding was seen as an important facilitating condition. Several actors need to anticipate on these barriers and facilitators in order to successfully implement quality indicators in palliative care services. Managers and directors should address the attitudes of the palliative caregivers towards quality measurement. Caregivers should be trained in using the indicators. Policy makers and administrators should develop tailored strategies in collaboration with the research field in order to create an optimal environment for palliative caregivers to be involved in systematic quality monitoring and improvement. Once the implementation process has started, the effectiveness of the implementation strategies needs to be further evaluated.

\section{Acknowledgments}

We thank all caregivers for their cooperation in the study. We thank Jane Ruthven for her help in language editing the manuscript. This study is realized with the support of Kom Op Tegen Kanker, a campaign of The Flemish League Against Cancer. The study is part of the Flanders Study to Improve End-of-Life Care and Evaluation Tools (FLIECE project), a collaboration between the Vrije Universiteit Brussel, Ghent University, the Katholieke Universiteit Leuven, Belgium, and VU University Medical Center Amsterdam, the Netherlands. Joachim Cohen and Lieve Van den Block are postdoctoral fellows of the Research Foundation Flanders.

\section{Conflict of interest}

The authors declare that there is no conflict of interest.

\section{REFERENCES}

1. Bowman KW, Martin DK, Singer PA (2000) Quality end-of-life care. J Eval Clin Pract 6(1):51-61

2. Lorenz KA, Lynn J, Dy SM, Shugarman LR, Wilkinson A, Mularski RA et al (2008)

Evidence for improving palliative care at the end of life: a systematic review. Ann Intern Med 148(2):147-59

3. Rosenfeld K, Wenger NS (2000) Measuring quality in end-of-life care. Clin Geriatr Med 16(2):387-400

4. Palliative care: a model for innovative health and social policies, 1649, Council of Europe (2009)

5. Dy SM, Lupu D, Seow H (2012) Progress towards systems of quality measurement that capture the essence of good palliative care. Palliat Med 26(4):291-3CrossRefPubMed

6. Ferrell B, Connor SR, Cordes A, Dahlin CM, Fine PG, Hutton N et al (2007) The national agenda for quality palliative care: the National Consensus Project and the National Quality Forum. J Pain Symptom Manag 33(6):737-44

7. Eagar K, Watters P, Currow DC, Aoun SM, Yates P (2010) The Australian Palliative Care Outcomes Collaboration (PCOC) - measuring the quality and outcomes of palliative care on a routine basis. Aust Health Rev 34(2):186-92

8. Lundstrom S, Axelsson B, Heedman PA, Fransson G, Furst CJ (2012) Developing a national quality register in end-of-life care: the Swedish experience. Palliat Med 26(4):31321

9. World Health Organisation (2006) Quality of care: a process for making strategic choices in health systems. WHO Press, Geneva

10. Campbell SM, Braspenning J, Hutchinson A, Marshall MN (2003) Research methods used in developing and applying quality indicators in primary care. BMJ 326(7393):816-9 
Leemans, K., Block, L. van den, Stichele, R. Vander, Francke, A.L., Deliens, L., Cohen, J. How to implement quality indicators successfully in palliative care services: perceptions of team members about facilitators of and barriers to implementation. Supportive Care in Cancer: 2015,7 23(12), 3503-3511

11. Ostgathe C, Voltz R (2010) Quality indicators in end-of-life care. Curr Opin Support Palliat Care 4(3):170-3

12. Shekelle PG, Maclean CH, Morton SC, Wenger NS (2001) Assessing care of vulnerable elders: methods for developing quality indicators. Ann Intern Med 135(8 Pt 2):647-52

13. Singer PA, Martin DK, Bowman K (2000) Quality end-of-life care: where do we go from here? J Palliat Med 3(4):403-5

14. Earle CC, Park ER, Lai B, Weeks JC, Ayanian JZ, Block S (2003) Identifying potential indicators of the quality of end-of-life cancer care from administrative data. J Clin Oncol 21(6):1133-8

15. Grunfeld E, Urquhart R, Mykhalovskiy E, Folkes A, Johnston G, Burge FI et al (2008) Toward population-based indicators of quality end-of-life care: testing stakeholder agreement. Cancer 112(10):2301-8

16. Sato K, Miyashita M, Morita T, Sanjo M, Shima Y, Uchitomi Y (2008) Reliability assessment and findings of a newly developed quality measurement instrument: quality indicators of end-of-life cancer care from medical chart review at a Japanese regional cancer center. J Palliat Med 11(5):729-37

17. Seow H, Snyder CF, Shugarman LR, Mularski RA, Kutner JS, Lorenz KA et al (2009) Developing quality indicators for cancer end-of-life care: proceedings from a national symposium. Cancer 115(17):3820-9

18. Pastrana T, Radbruch L, Nauck F, Hover G, Fegg M, Pestinger M et al (2009) Outcome indicators in palliative care-how to assess quality and success. Focus group and nominal group technique in Germany. Support Care Cancer 18(7):859-868

19. Claessen SJ, Francke AL, Belarbi HE, Pasman HR, van der Putten MJ, Deliens L (2011) A new set of quality indicators for palliative care: process and results of the development trajectory. J Pain Symptom Manag 42(2):169-82

20. de Roo ML, Leemans K, Claessen SJ, Cohen J, Pasman HR, Deliens L et al (2013) Quality indicators for palliative care: update of a systematic review. J Pain Symptom Manag 46(4):556-72

21. Leemans K, Cohen J, Francke AL, Vander Stichele RV, Claessen SJ, van den Block L et al (2013) Towards a standardized method of developing quality indicators for palliative care: protocol of the Quality Indicators for Palliative Care (Q-PAC) study. BMC Palliat Care 12(1):6CrossRefPubMedCentralPubMed

22.Leemans K, Deliens L, Francke AL, Vander Stichele R, van den Block L, Cohen J (2015) Quality indicators for palliative care services (Q-PAC): mixed methods study testing for face validity, feasibility, discriminative power and usefulness. Palliat Med 29(1):71-82

23.Meiland FJ, Droes RM, de Lange J, Vernooij-Dassen MJ (2004) Development of a theoretical model for tracing facilitators and barriers in adaptive implementation of innovative practices in dementia care. Arch Gerontol Geriatr Suppl 9:279-90

24.Meiland FJ, Droes RM, de Lange J, Vernooij-Dassen MJ (2005) Facilitators and barriers in the implementation of the meeting centres model for people with dementia and their carers. Health Policy 71(2):243-53d

25.Grol R, Wensing M (2011) Implementatie: effectieve verbetering van de patiëntenzorg. vierde herziene druk ed. Reed Business, Amsterdam

26.Grol R, Wensing M (2004) What drives change? Barriers to and incentives for achieving evidence-based practice. Med J Aust 180(6 Suppl):S57-S60PubMed

27.de Vos ML, van der Veer SN, Graafmans WC, de Keizer NF, Jager KJ, Westert GP et al (2010) Implementing quality indicators in intensive care units: exploring barriers to and facilitators of behaviour change. Implement Sci 5:52CrossRefPubMedCentralPubMed

28.Vasse E, Spijker A, Meiland F, Rikkert MO, Moniz-Cook E, Vernooij-Dassen M (2012) Barriers and facilitators in implementing quality indicators for psychosocial dementia care in European countries. In: Vasse E (ed) A stepwise process for developing and implementing quality indicators to improve psychosocial dementia care in European countries. Uitgeverij BOXpress, Nijmegen

29.Emanuel EJ, Emanuel LL (1998) The promise of a good death. Lancet 351(Suppl 2):SII21-SII29

30.Singer PA, Martin DK, Kelner M (1999) Quality end-of-life care: patients' perspectives. JAMA 281(2):163-8 
Leemans, K., Block, L. van den, Stichele, R. Vander, Francke, A.L., Deliens, L., Cohen, J. How to implement quality indicators successfully in palliative care services: perceptions of team members about facilitators of and barriers to implementation. Supportive Care in Cancer: 2015,7 23(12), 3503-3511

31.Steinhauser KE, Clipp EC, McNeilly M, Christakis NA, Mclntyre LM, Tulsky JA (2000) In search of a good death: observations of patients, families, and providers. Ann Intern Med 132(10):825-32

32.Teno JM, Casey VA, Welch LC, Edgman-Levitan S (2001) Patient-focused, familycentered end-of-life medical care: views of the guidelines and bereaved family members. $J$ Pain Symptom Manag 22(3):738-51

33.Morgan D, Krueger R (1998) Planning focus groups. Series: focus group kit. SAGE Publications, Thousand 34.Pope C, Ziebland S, Mays N (2000) Qualitative research in health care. Analysing qualitative data. BMJ 320(7227):114-6

35.Addington D, Kyle T, Desai S, Wang J (2010) Facilitators and barriers to implementing quality measurement in primary mental health care: systematic review. Can Fam Physician 56(12):1322-31

36.Antunes B, Harding R, Higginson IJ (2014) Implementing patient-reported outcome measures in palliative care clinical practice: a systematic review of facilitators and barriers. Palliat Med 28(2):158-75

37.Duncan EA, Murray J (2012) The barriers and facilitators to routine outcome measurement by allied health professionals in practice: a systematic review. BMC Health Serv Res 12:96

38. Hughes RG (2008) Tools and strategies for quality improvement and patient safety. In: Patient safety and quality: an evidence-based handbook for nurses. Agency for Healthcare Research and Quality, Rockville

\section{TABLES AND FIGURES}

Table 1 Interview guide and accompanying prompts for discussion during the focus group interviews

\begin{tabular}{|l|l|}
\hline Question & Prompt \\
\hline $\begin{array}{l}\text { 1.Would you in the future consider working with } \\
\text { quality indicators within your palliative care } \\
\text { service? }\end{array}$ & $\begin{array}{l}\text { What are your expectations } \\
\text { about working with quality } \\
\text { indicators? }\end{array}$ \\
\hline $\begin{array}{l}\text { 2.How would you use the quality indicators, as } \\
\text { presented in the manual, within the working of your } \\
\text { palliative care service? }\end{array}$ & $\begin{array}{l}\text { What might be the problems? } \\
\text { What might be the solutions? }\end{array}$ \\
\hline $\begin{array}{l}\text { 3.Do you consider it possible to independently use } \\
\text { the quality indicators, as presented in the manual? }\end{array}$ & $\begin{array}{l}\text { What might be the problems? } \\
\text { What might be the solutions? }\end{array}$ \\
\hline
\end{tabular}


Leemans, K., Block, L. van den, Stichele, R. Vander, Francke, A.L., Deliens, L., Cohen, J. How to implement quality indicators successfully in palliative care services: perceptions of team members about facilitators of and barriers to implementation. Supportive Care in Cancer: 2015,7 23(12), 3503-3511

Fig. 1 Schematic representation of how to measure the quality indicators for palliative care

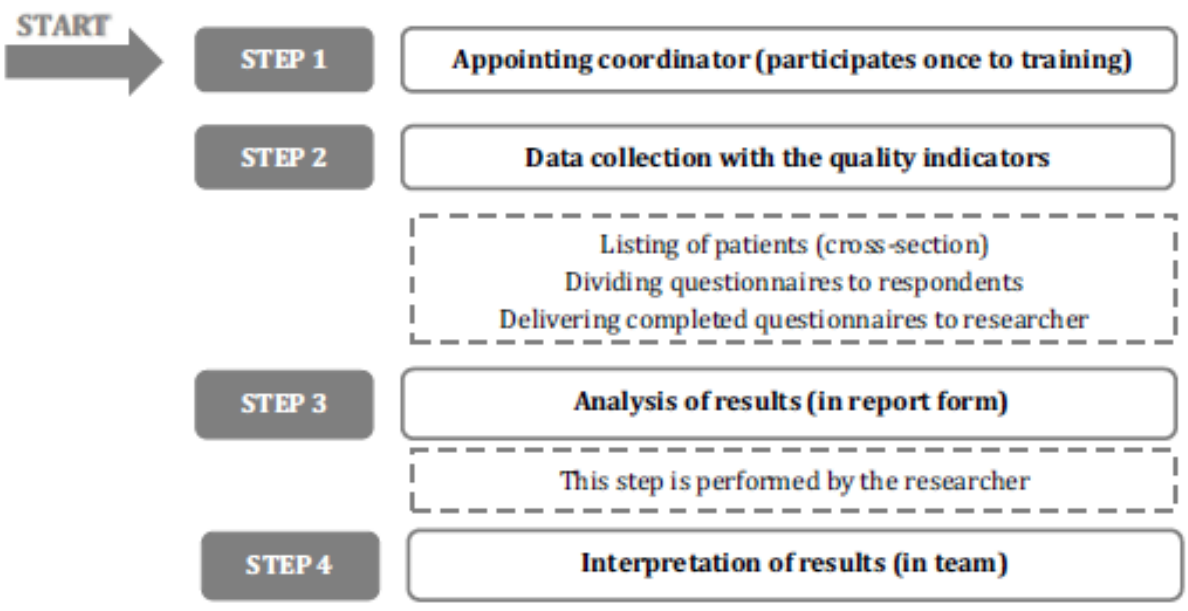

STEP 5

Taking action to improve the care (in team)

STEP 6

Planning next measurement (setting a date) 
Leemans, K., Block, L. van den, Stichele, R. Vander, Francke, A.L., Deliens, L., Cohen, J. How to implement quality indicators successfully in palliative care services: perceptions of team members about facilitators of and barriers to implementation. Supportive Care in Cancer: 2015,7 23(12), 3503-3511

Table 2 : Overview of participants per specialism in the three focus group interviews

\begin{tabular}{|l|l|l|l|}
\hline \multicolumn{1}{|c|}{} & \multicolumn{2}{c|}{ Focus group interviews } \\
\cline { 2 - 3 } \multicolumn{1}{|c|}{ PCU } & PST & MHT \\
\hline No. of teams involved & 7 & 7 & 4 \\
\hline No. of caregivers per specialism & \\
\hline Head nurse & 4 & 3 & 1 \\
\hline Nurse & 1 & 2 & 1 \\
\hline Physician & - & 1 & - \\
\hline Psychologist & 2 & 2 & 2 \\
\hline Other ${ }^{\text {a }}$ & - & 1 & 1 \\
\hline Total & 7 & 9 & 5 \\
\hline Experience with QIs & & & \\
\hline Yes & 1 & 2 & 1 \\
\hline No & 6 & 7 & 4 \\
\hline
\end{tabular}

PCU palliative care unit, PST palliative support team, MHT multidisciplinary palliative home care team

${ }^{\mathrm{a}}$ For the PSTs, one quality coordinator joined the focus group interview; for the MHTs, one coordinator of a palliative network participated

Table 3 : Conditions facilitating or impeding the implementation of quality indicators in palliative care at different levels of the healthcare system and per type of care service

\section{Condition facilitating (f) or impeding (i) implementation}

Mentioned in focus group

PCU PST MHT

Attitudes of the team regarding quality measurement (i.e., level of the innovation)

Presence of a need to demonstrate quality of care (f)

An identified need for evidence-based improvement trajectories (f)

Presence of a desire to exchange ideas with and learn from other palliative care services (f)

Attitudes, knowledge, and skills within the team (i.e., level of the individual caregiver)

Perceptions of quality indicators as an individual evaluation (i)

Lack of knowledge and skills to work with quality indicators (i)

Attitude of quality measurement as something outside the responsibility of caregivers (i)

\begin{tabular}{l|l|l|l|}
\hline+ & + & + \\
++ & + & + \\
+ & + & +
\end{tabular}

(i)

\begin{tabular}{|l|l|l|}
\hline & & + \\
\hline+ & + & \\
\hline+ & + & +
\end{tabular}


Leemans, K., Block, L. van den, Stichele, R. Vander, Francke, A.L., Deliens, L., Cohen, J. How to implement quality indicators successfully in palliative care services: perceptions of team members about facilitators of and barriers to implementation. Supportive Care in Cancer: 2015,7 23(12), 3503-3511

\section{Condition facilitating (f) or impeding (i) implementation}

\section{Mentioned in focus} group

\section{PCU PST MHT}

Anxiety about harming respondents to the questionnaires (i.e., level of the respondents)

Anxiety about harming vulnerable patients and families (i)
Anxiety about influencing the relationship with the family physician
(i)

Structure and organization of care (i.e., level of organizational context)

\begin{tabular}{|l|l|l|}
\hline Lack of time and staff to perform quality measurement (i) \\
\hline Instabilities in the team (i) \\
\hline Presence of electronic patient records (f) \\
\hline Presence of a good leader to guide the quality measurement (f) \\
\hline Interest in quality management from the directors (f) \\
\hline Level of economic and political context \\
\hline $\begin{array}{l}\text { Willingness to transfer results of quality measurement to the } \\
\text { government (f) }\end{array}$ \\
\hline Reimbursement for using quality indicators (f) \\
\hline Possibility to link quality indicators to hospital accreditation (f)
\end{tabular}

PCU palliative care unit, PST palliative support team, MHT multidisciplinary palliative home care team 